Oliver H.G. Wilder-Smith $\mathrm{MBCHB} M \mathrm{MD}$, ${ }^{*}$ Patrick A. Ravussin $M D, \dagger$ Laurent A. Decosterd PhD, $\ddagger$ Paul A. Despland MD, $\mathfrak{S}$ Bruno Bissonnette MDI

\section{Midazolam premedica- tion reduces propofol dose requirements for multiple anesthetic endpoints}

Purpose: This study investigates the interactions between midazolam premedication and propofol infusion induction of anesthesia for multiple anesthetic endpoints including: loss of verbal contact (LVC; hypnotic), dropping an infusion flex (DF; motor), loss of reaction to painful stimulation (LRP; antinociceptive) and attainment of electroencephalographic burst suppression (BUR; EEG).

Methods: In a double blind, controlled, randomized and prospective study, 24 ASA I-II patients received either midazolam 0.05 $\mathrm{mg} \cdot \mathrm{kg}^{-1}(\mathrm{PM} ; n=13)$ or saline placebo $(\mathrm{PO} ; n=1 \mathrm{I}) \mathrm{N}$ as premedication. Twenty minutes later, anesthesia was induced by propofol infusion at $30 \mathrm{mg}^{\mathrm{kg}} \mathrm{kg}^{-1} \mathrm{hr}^{-1} . \mathrm{ED}_{50^{\prime}} \mathrm{ED}_{95}$ and group medians for times and doses were determined and compared at multiple anesthetic endpoints.

Results: At the hypnotic, motor and EEG endpoints, midazolam premedication significantly and similarly reduced propofol $\mathrm{ED}_{50}$ (reduction: $18 \%, 13 \%$ and $20 \%$ respectively; $P<0.05$ vs unpremedicated patients) and $\mathrm{ED}_{95}$ (reduction: $20 \%, 11 \%$ and $20 \%$ respectively; $P<0.05$ vs unpremedicated patients). For antinociception (LRP), dose reduction by premedication was greater for propofol $\mathrm{ED}_{95}$ (reduction: $41 \%$; $P<0.05$ vs unpremedicated patients) than $\mathrm{ED}_{50}$ (reduction: $18 \% ; P<0.05$ is unpremedicated patients). Hemodynamic values were similar in both groups at the various endpoints.

Conclusions: Midazolam premedication 20 min prior to induction of anesthesia reduces the propofol doses necessary to attain the multiple anesthetic endpoints studied without affecting hemodynamics in this otherwise healthy population. The interaction differs for different anesthetic endpoints (e.g., antinociception vs hypnosis) and propofol doses (e.g., $\mathrm{ED}_{50}$ vs $\mathrm{ED}_{95}$ ).
Objectif : Examiner les interactions entre la prémédication avec du midazolam et l'induction de l'anesthésie avec une perfusion de propofol en regard de divers paramètres comprenant : la perte du contact verbal ( $P C V$; hypnotique), le relâchement de la main (RM; moteur), l'absence de réaction à une stimulation douloureuse (ARD; antinociceptif) et la suppression des salves d'activité électroencéphalographiques (SUP; EEG).

Méthodes : L'étude prospective, contrôlée, randomisée et à double insu concerne 24 patients ASA I-II qui ont reçu, soit $0,05 \mathrm{mg} \cdot \mathrm{kg}^{-1}$ de midazolam (PM; $n=13)$, soit une solution salée placebo (PO; $n=11) \mathrm{iv}$ comme prémédication. L'anesthésie a été induite, 20 min plus tard, avec une perfusion de propofol a $30 \mathrm{mg} \cdot \mathrm{kg}^{-1} \cdot \mathrm{hr}^{-1}$. Les ED50, ED95 et les médianes pour les temps et les doses dans chaque groupe ont été déteminées et comparées pour divers paramètres anesthésiques.

Résultats : Pour les variables hypnotique, motrice et EEG, la prémédication au midazolam a réduit pareillement et de façon significative la $E D_{50}$ de propofol (réduction : $18 \%, 13 \%$ et $20 \%$ respectivement; $P$ $<0,05$ v les patients sans prémédication) et la $E D_{95}$ (réduction: $20 \%$, $11 \%$ et $20 \%$ respectivement; $P<0,05$ vs les patients sans prémédication). Concernant l'antinociception (ARD), la réduction de la dose par la prémédication a été plus importante pour la $E D_{95}$ de propofol (réduction: $41 \% ; P<0,05$ vs les patients sans prémédication) que pour la $E D_{50}$ (réduction : $18 \% ; P<0,05$ vs les patients sans prémédication). Les valeurs hémodynamiques ont été similaires chez les patients des deux groupes quant aux divers paramètres étudiés.

Conclusions : La prémédication avec du midazolam, 20 min avant l'induction de l'anesthésie, permet de réduire les doses de propofol nécessaires à l'atteinte des divers objectifs anesthésiques étudiés sans modifer l'hémodynamie chez une population de patients en bonne santé. Les interactions different en fonction des paramètres anesthésiques (ex., l'antinociception vs l'hypnose) et selon les doses de propofol (ex., ED 50 vs $E D_{9,5}$ ).

From the Nociception Research Group Berne University, Berne, ${ }^{*}$ the Department of Anaesthesiology Sion Hospital, $\dagger$ the Division of Clinical Pharmacology, $\ddagger$ the Department of Neurology, $\$$ Lausanne University Hospital (CHUV), Lausanne, Switzerland and the Department of Anaesthesia, I University of Toronto, Toronto, Canada.

Address correspondence to. Dr. Oliver H.G. Wilder-Smith, The Pain Centre, University Department of Anaesthesiology, Academisch Ziekenhuis Nijmegen, P.O. Box 9101, NL-6500 HB Nijmegen, The Netherlands. Phone: $+31-24-36144$ 06; Fax: +31-24-361 35 85; E-mail: o.wildersmith@anes.azn.nl

Work was carried out at the Department of Anaesthesiology, Lausanne University Hospital (CHUV), Lausanne, Switzerland.

Part of the study was presented at the 1995 Atlanta ASA meeting.

Financial Support: Partially supported by a grant from Roche Pharma (Switzerland) A.G.

Accepted for publication January 11, 2001. 
$\mathrm{D}$ RUG combinations are used frequently in clinical anesthesia. As well as widening the spectrum of action of anesthesia, the use of combinations can also decrease side effects, mainly by reducing the doses of individual drugs necessary via synergism.

Because anesthesia is the result of several different actions, such as hypnosis, antinociception or myorelaxation, studies of anesthetic drug interactions should ideally include multiple endpoints involved in anesthesia. However, most studies involving anesthetic drug interactions have so far investigated only single clinical endpoints, usually the hypnotic endpoint of loss of verbal contact or eyelash reflex, using single iv bolus techniques. Infusion induction titration models ${ }^{1-3}$ represent an interesting and increasingly validated alternative to bolus models for the study of drug interactions. They permit the evaluation of multiple endpoints in one patient and session, include the clinically important time element and are easy to apply to clinical practice. Using such a model, we have recently been able to show that for thiopental, the interaction with midazolam premedication differs according to the anesthetic endpoint studied. ${ }^{3}$

Midazolam is a popular adjuvant drug for $i v$ anesthesia. It has been demonstrated to be hypnotically synergistic with propofol as a premedicant or $\mathrm{CO}^{-}$ inductant during induction using bolus techniques. ${ }^{4-6}$ To our knowledge, the interactions of midazolam premedication with propofol have not been studied for multiple anesthetic endpoints. This investigation is designed to quantify the interaction of midazolam with propofol at multiple anesthetic endpoints using an infusion induction titration model.

\section{Methods}

After institutional Review Board and Ethics Committee approval as well as written informed patient consent, 24 ASA physical status I-II patients scheduled for elective back surgery were prospectively included in the study. Exclusion criteria comprised cardiovascular and neurological disease, diabetes mellitus, chronic hypnotic or analgesic medication and abnormal body weight (over $20 \%$ deviation from ideal).

In the operating room, the electrodes for the electroencephalogram (EEG) were applied to the unpremedicated patients, an awake EEG obtained, and the patients allocated to receive either midazolam $0.05 \mathrm{mg} \cdot \mathrm{kg}^{-1}$ iv (PM; $\left.n=13\right)$ or placebo $(\mathrm{NaCl} 0,9 \%)$ $(\mathrm{P} 0 ; n=11)$ by use of a random number table. Twenty minutes before anesthesia induction a person not involved in the study performed slow iv premedication (injection over $30 \mathrm{sec}$ ) of the patients. This design was chosen to simulate typical iv premedication (as opposed to co-induction) at our institution and also permitted us to obtain a stable baseline EEG under the influence of midazolam. Neither the investigator nor the person interpreting the EEG knew whether the patient had been premedicated or not. The EEG was interpreted by an experienced electroencephalographer, present throughout the study period.

Monitoring devices were next installed and the patient pre-oxygenated by face mask. Lung ventilation was assisted or controlled from induction onwards to maintain normal respiratory values $\left(\mathrm{FiO}_{2}=1.0 ; \mathrm{SpO}_{2}\right.$ $>95 \% ; \mathrm{ETCO}_{2}=4-5 \mathrm{kPa}$ ). Anesthesia was induced by a continuous iv infusion of propofol $1 \%$ solution by syringe pump (Perfusor $\mathbb{R}$, Braun Melsungen, Germany) at $30 \mathrm{mg} \cdot \mathrm{kg}^{-1} \cdot \mathrm{hr}^{-1}$ until the appearance of burst suppression on the EEG.

Continuous EEG recording (standard 10-20 system 16 channel montage, Medilog $($, Oxford, UK) was started five minutes before ip premedication and acquired until the end of the study. Arterial blood pressure (non-invasive, automated oscillometry) and heart rate (ECG monitor) were measured at one-minute intervals and recorded specifically at four endpoints. The following endpoints were determined and documented on the EEG record: 1) hypnotic: loss of verbal contact (LVC), by questioning every ten seconds "please open your eyes"; 2) motor: drop flex (DF), time at which a $500-\mathrm{ml}$ plastic infusion bag held in the hand was dropped; 3 ) antinociceptive: loss of reaction to pain (LRP), time at which purposeful somatic movement to transcutaneous constant current tetanic electric stimulation by a nerve stimulator ceased (Digistim ${ }^{\circledR}$, Biometer A/S, Copenhagen, DK; stimulation started after LVC and DF was applied via self adhesive electrodes on the side of the index finger at $100 \mathrm{~Hz} / 40 \mathrm{~mA} / 0.2 \mathrm{msec}$ and avoided stimulating major nerves); and 4) electroencephalographic: burst suppression (BUR) (first occurrence of three seconds isoelectricity between bursts in the dominant side, fronto-parietal channel).

The times and cumulative propofol doses at each endpoint were recorded. Vecuronium $0.1 \mathrm{mg} \cdot \mathrm{kg}^{-1}$ to facilitate intubation was given only after the patient ceased reacting to painful stimulation. On reaching EEG burst suppression, the trachea was intubated and the study ended.

\section{Statistical analysis}

Using data from bolus studies by Short ${ }^{4}, 5$ and Vinik ${ }^{6}$ and infusion model data from Peacock, ${ }^{7}$ we estimated the group size necessary to detect a clinically relevant difference of $20 \%$ in $\mathrm{ED}_{50}$ values for loss of verbal contact to be 11 (alpha $=5 \%$; beta $=10 \%$; two-tailed). As 
TABLE I Mean arterial pressures and heart rates, and median times and doses at endpoints

\begin{tabular}{|c|c|c|c|c|c|c|}
\hline Group & Epent & $\begin{array}{l}M A P \\
(m m H g)\end{array}$ & $\begin{array}{l}H R \\
\left(\mathrm{~min}^{-1}\right)\end{array}$ & $\begin{array}{l}\text { Time } \\
(\mathrm{sec})\end{array}$ & $\begin{array}{l}\text { Dose } \\
\left(m g \cdot k g^{-1}\right)\end{array}$ & $\begin{array}{l}\text { Dose ratio } \\
(P O: P M\end{array}$ \\
\hline P0 & BL & $94(12)$ & $77(14)$ & - & - & - \\
\hline PM & BL & $88(16)$ & $76(12)$ & - & - & \\
\hline P0 & $\mathrm{LVC}$ & $89(12)$ & $78(15)$ & $\begin{array}{l}232 \\
(120-400) \dagger\end{array}$ & $\begin{array}{l}1.9 \\
(1.0-3.3) \dagger\end{array}$ & 1.3 \\
\hline PM & LVC & $90(18)$ & $74(12)$ & $\begin{array}{l}180 \\
(105-287) \dagger\end{array}$ & $\begin{array}{l}1.5 \\
(0.9-2.4) \dagger\end{array}$ & \\
\hline $\mathrm{PO}$ & DF & $89(10)$ & $77(14)$ & $\begin{array}{l}220 \\
(121-360) \dagger\end{array}$ & $\begin{array}{l}1.8 \\
(1.0-3.0) \dagger\end{array}$ & 1.2 \\
\hline PM & DF & $88(21)$ & $77(12)$ & $\begin{array}{l}180 \\
(100-273) \dagger\end{array}$ & $\begin{array}{l}1.5 \\
(0.8-2.3) \dagger\end{array}$ & \\
\hline P0 & LRP & $85(12)$ & $78(17)$ & $\begin{array}{l}381 \\
(216-790)^{*}\end{array}$ & $\begin{array}{l}3.2 \\
(1.8-6.6)^{\star}\end{array}$ & 1.2 \\
\hline PM & LRP & $87(20)$ & $79(14)$ & $\begin{array}{l}310 \\
(220-515)^{*}\end{array}$ & $\begin{array}{l}2.6 \\
(1.8-4.3)^{*}\end{array}$ & \\
\hline P0 & BUR & $82(15)$ & $81(14)$ & $\begin{array}{l}569 \\
(390-1212)^{*} \dagger\end{array}$ & $\begin{array}{l}4.7 \\
(3.3-10.1)^{*} \dagger\end{array}$ & 1.1 \\
\hline PM & BUR & $86(17)$ & $85(11)$ & $\begin{array}{l}473 \\
(290-885)^{*} \dagger\end{array}$ & $\begin{array}{l}4.3 \\
(2.4-7.4)^{*} \dagger\end{array}$ & \\
\hline
\end{tabular}

Data presented as mean and standard deviation (hemodynamics) or median and $95 \%$ confidence interval (times and doses) at the different endpoints.

$\mathrm{LVC}=$ loss of verbal contact; $\mathrm{DF}=\mathrm{drop}$ flex; $\mathrm{LRP}=$ loss of response to pain; $\mathrm{BUR}=\mathrm{EEG}$ burst suppression; $\mathrm{BL}=$ baseline; $\mathrm{P} 0=\mathrm{group}$ without midazolam premedication; $\mathrm{PM}=$ group with midazolam premedication; Dose ratio=potency ratio for doses; ${ }^{*}=$ significantly different from $L V C$ value; $\dagger=$ significantly different from LRP value $(P<0.05)$.

these results are of limited applicability to our study, we pre-planned post hoc power testing based on results at LVC and BUR.

Patients' physical characteristics and median times and doses at endpoints were compared using MannWhitney U or Wilcoxon signed rank testing as appropriate. Hemodynamic data were analysed with repeated measures ANOVA and post hoc Tukey testing. The endpoint dose ratios DF:LVC, LRP:LVC and BUR:LVC were calculated and their medians compared non-parametrically (Mann-Whitney U or Wilcoxon). To investigate dose-response relationships, the percentage response rate (percent patients attaining endpoint) was probit-transformed and multiple linear regression analysis of the resulting probit response $\log$ dose curves performed. $\mathrm{ED}_{50}$ and $\mathrm{ED}_{95}$ values were calculated and $95 \%$ confidence intervals estimated. The significance of $\mathrm{ED}_{50}$ and $\mathrm{ED}_{95}$ differences within or between groups was assessed using Students' $t$ testing (paired or unpaired as appropriate). The same procedure was applied to comparisons of regression curve parallelism via regression coefficients and the significance of parallel curve shifts via intercepts. For all statistical analyses, multiple testing was Bonferroni-corrected as necessary, and $P<0.05$ considered statistically significant.
Results

The study was completed without incident. The patients in the groups were similar with regard to age (without midazolam, P0: $46 \pm 15$; with midazolam, PM: $48 \pm 11$ yr), weight (P0: $72 \pm 12 ; \mathrm{PM}: 72 \pm 12 \mathrm{~kg}$ ) (means \pm standard deviations) and sex ratio (M:F; P0: 5:6; PM: 9:4). Post hoc power testing, based on results at the hypnotic (LVC) and EEG (BUR) endpoints, demonstrated that the group size $(n=11)$ was more than adequate to demonstrate clinically relevant differences of $20 \%$ (alpha $=5 \%$; beta $=10 \%$; two-tailed testing).

Premedication did not significantly affect median values of time to, dose at, and hemodynamics at any endpoint (Table I). In both patient groups, median times and doses at the motor (DF, drop flex) and hypnotic (LVC, loss of verbal contact) endpoints were similar. At antinociceptive (LRP) and EEG (BUR) endpoints, these values were significantly greater than at the hypnotic endpoint for premedicated and unpremedicated patients. The antinociceptive endpoint was statistically distinct from all other endpoints in both groups for times and doses. The median dose potency ratios (i.e., median dose at given endpoint for unpremedicated patients divided by median dose at same endpoint for premedicated patients) were similar for all endpoints. The relationship between the dose at 
the hypnotic endpoint and dose at the other endpoints was similar for both patient groups (Table II).

Premedication did, however, significantly lower $\mathrm{ED}_{50}$ and $\mathrm{ED}_{95}$ values at all endpoints (Figure, Table III) with one exception $\left(\mathrm{ED}_{95}\right.$ at the motor endpoint, $\mathrm{DF})$. In both patient groups, the hypnotic endpoint (LVC) was statistically distinct from the antinociceptive (LRP) and EEG (BUR) endpoints for $\mathrm{ED}_{50}$ and $\mathrm{ED}_{95}$

TABLE II Median endpoint ratios compared to LVC

\begin{tabular}{llll}
\hline Group & DF:LVC & LRP:LVC & BUR:LVC \\
\hline P0 (dose) & $1.0(0.5-2.0)$ & $2.0(1.3-3.3)$ & $3.0(2.1-4.3)$ \\
PM (dose) & $1.0(0.6-1.3)$ & $2.0(1.3-3.2)$ & $2.8(2.0-3.6)$ \\
\hline
\end{tabular}

Results are medians of ratio "endpoint dose divided by LVC dose" and $95 \%$ confidence intervals.

$\mathrm{LVC}=$ loss of verbal contact; $\mathrm{DF}=$ drop flex, $\mathrm{LRP}=$ loss of response to pain; and BUR=EEG burst suppression. $\mathrm{P} 0$ =group without midazolam premedication; $\mathrm{PM}=$ group with midazolam premedication. There are no statistically significant differences between the groups at any point.
As for median doses, $\mathrm{ED}_{50}$ and $\mathrm{ED}_{95}$ dose potency ratios (i.e., dose at given endpoint for premedicated patients divided by dose at same endpoint for unpremedicated patients) were alike for the hypnotic, motor and EEG endpoints. For the antinociceptive endpoint, dose reduction with midazolam premedication increased from $\mathrm{ED}_{5}$ to $\mathrm{ED}_{95}$ from $18 \%$ to $41 \%$. This was brought about by significant steepening of the propofol dose-response curve for antinociception with premedication, bringing its slope to a value close to that of the other dose-response curves, generally similar for all other endpoints in both patient groups.

\section{Discussion}

Midazolam premedication decreases the dose of propofol necessary to reach all the anesthetic endpoints investigated. In this otherwise healthy patient population, there were no accompanying changes in hemodynamic behaviour for the drug doses studied. For antinociception, dose reduction accompanying midazolam premedication markedly increases with increasing propofol dosage (i.e., from $\mathrm{ED}_{50}$ to $\mathrm{ED}_{95}$ ).
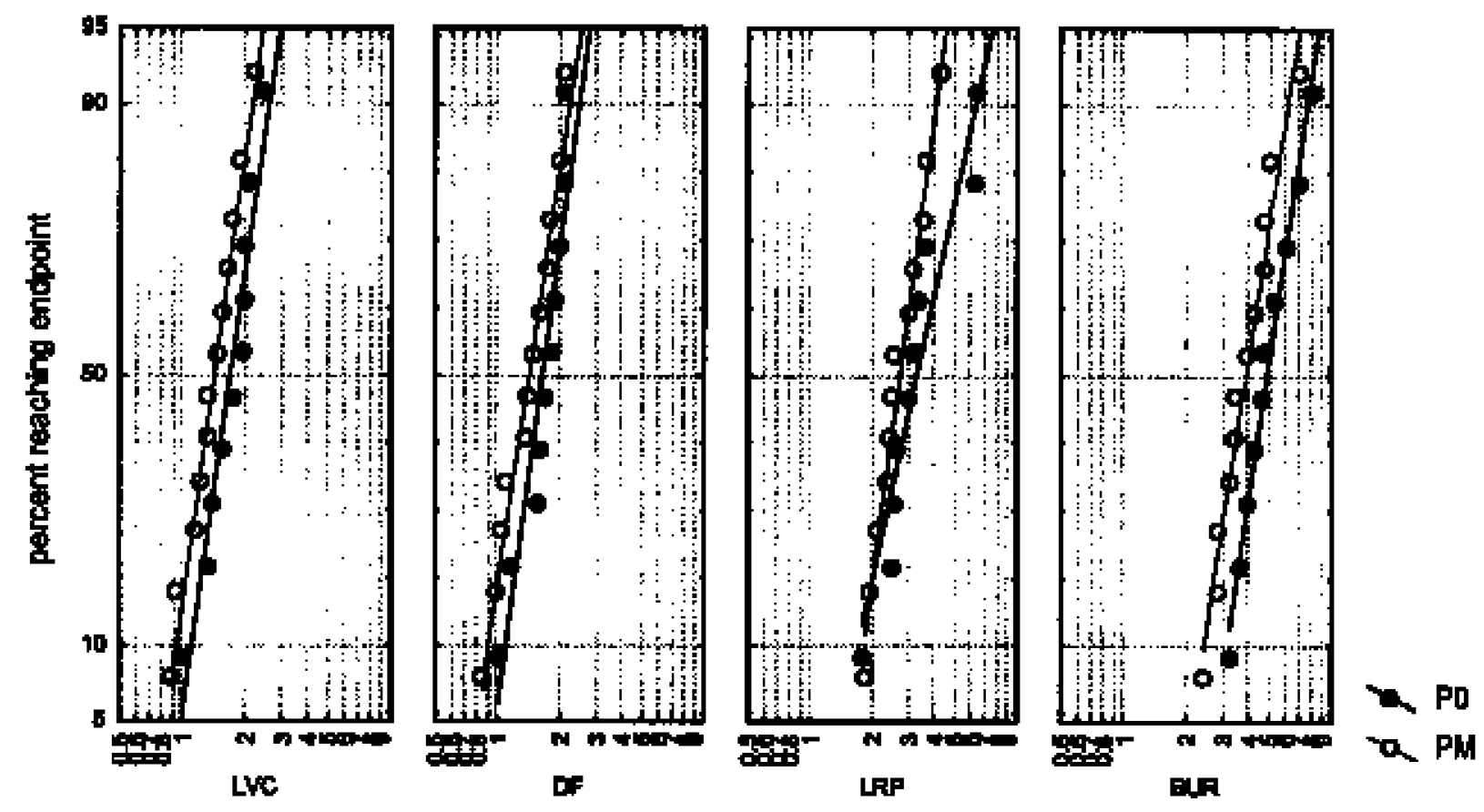

does (mplap)

FIGURE Multiple linear regression curves for log dose propofol $p s$ probit response at hypnotic (loss of verbal contact; LVC), motor (dropping of infusion bag; DF), antinociceptive (loss of reaction to pain; LRP) and EEG (attainment of burst suppression; BUR) end points. $\mathrm{P} 0=$ goup without midazolam premedication; $\mathrm{PM}=$ group with midazolam premedication. Details of the curve characteristics are given in Table III. 
Wilder-Smith et al:: PROPOFOL-MIDAZOLAM INTERACTIONS

TABLE III Results: log dose - probit response multiple linear regression analysis

\begin{tabular}{|c|c|c|c|c|c|c|c|c|c|c|}
\hline Group & Epent & $R$ & $R^{2}$ & $P$ & Intercept & Slope & $E D_{50}$ & $R E D_{50}$ & $E D_{95}$ & $R E D_{95}$ \\
\hline Po \# & LVC & 0.97 & 0.94 & 0.000003 & $-1.61 \pm 0.15$ & $3.00 \pm 0.26$ & $\begin{array}{l}1.7 * \\
(1.6-1.8)\end{array}$ & 1.2 & $\begin{array}{l}3.0 * \\
(2.7-3.4)\end{array}$ & 1.3 \\
\hline PM & LVC & 0.99 & 0.98 & 0.000000 & $-1.05 \pm 0.06$ & $3.08 \pm 0.13$ & $\begin{array}{l}1.4 \\
(1.3-1.5)\end{array}$ & & $\begin{array}{l}2.4 \\
(2.3-2.5)\end{array}$ & \\
\hline P0\$ & DF & 0.94 & 0.87 & 0.00005 & $-1.58 \pm 0.22$ & $3.13 \pm 0.40$ & $\begin{array}{l}1.6^{*} \\
(1.5-1.8)\end{array}$ & 1.1 & $\begin{array}{l}2.8 \\
(2.4-3.5)\end{array}$ & 1.1 \\
\hline PM & DF & 0.98 & 0.97 & 0.000000 & $-0.96 \pm 0.07$ & $2.82 \pm 0.16$ & $\begin{array}{l}1.4 \\
(1.3-1.5)\end{array}$ & & $\begin{array}{l}2.5 \\
(2.3-2.8)\end{array}$ & \\
\hline $\mathrm{P} 0 \$$ & LRP & 0.95 & 0.89 & 0.00003 & $-2.33 \pm 0.29$ & $1.95 \pm 0.23$ & $\begin{array}{l}3.3^{*} \dagger \\
(2.9-3.7)\end{array}$ & 1.2 & $\begin{array}{l}7.6^{*} \dagger \\
(6.2-10.6)\end{array}$ & 1.7 \\
\hline PM & LRP & 0.99 & 0.98 & 0.000000 & $-3.13 \pm 0.15$ & $3.16 \pm 0.15$ & $\begin{array}{l}2.7 \dagger \\
(2.6-2.8)\end{array}$ & & $\begin{array}{l}4.5 \dagger \\
(4.3-4.8)\end{array}$ & \\
\hline P0 \# & BUR & 0.99 & 0.98 & 0.000000 & $-4.60 \pm 0.22$ & $2.88 \pm 0.13$ & $\begin{array}{l}4.9 * \dagger \\
(4.8-5.1)\end{array}$ & 1.3 & $\begin{array}{l}8.7{ }^{*} \dagger \\
(8.1-9.3)\end{array}$ & 1.2 \\
\hline PM & BUR & 0.98 & 0.97 & 0.000000 & $-3.74 \pm 0.23$ & $2.77 \pm 0.16$ & $\begin{array}{l}3.9 \dagger \\
(3.7-4.0)\end{array}$ & & $\begin{array}{l}7.0 \dagger \\
(6.4-7.6)\end{array}$ & \\
\hline
\end{tabular}

The results of multiple linear regression analysis of log dose $p s$ probit response curves are displayed. Slopes and intercepts are means \pm standard deviations; $\mathrm{ED}_{50}$ and $\mathrm{ED}_{95}$ values $\left(\mathrm{mg} \cdot \mathrm{kg}^{-1}\right)$ are medians and $95 \%$ confidence intervals. $\mathrm{RED}_{50}$ and $\mathrm{RED}_{95}$ are potency ratios $(\mathrm{P} 0 / \mathrm{PM})$ for $\mathrm{ED}_{50}$ and $\mathrm{ED}_{95}$ values.

$\mathrm{P} 0=$ group without midazolam premedication; $\mathrm{PM}=$ group with midazolam premedication. $\mathrm{LVC}=$ loss of verbal contact; $\mathrm{DF}=\mathrm{drop}$ flex; $\mathrm{LRP}=$ loss of response to pain; BUR=EEG burst suppression.

$P$ values in the Table refer to the fit of the curve.

* =significantly different from PM value; $\dagger=$ significantly different from LVC value $(P<0.05)$. \#=P0 and PM curves are statistically parallel (slope), significant shift present (intercept); $\$=$ curves are not parallel.

The anesthetic endpoints hypnosis, antinociception and EEG burst suppression are statistically distinct with regard to doses and times in both patient groups. Premedication does not alter the relationship between dose to reach the hypnotic endpoint and dose to reach other study endpoints.

We have found no other studies investigating the interaction between midazolam premedication and propofol for multiple anesthetic endpoints during infusion induction of anesthesia. In patients undergoing induction of anesthesia with a propofol infusion at 33.3 $\mathrm{mg} \cdot \mathrm{min}^{-1}$ and premedicated with oral temazepam and fentanyl $0.75 \mu \mathrm{g} \cdot \mathrm{kg}^{-1} \mathrm{iv}$, Peacock $e t \mathrm{al}^{7}$ determined a mean induction time of $145 \mathrm{sec}$ and a mean induction dose of $1.36 \mathrm{mg} \cdot \mathrm{kg}^{-1}$, similar to our results in the midazolam-premedicated group (medians: $180 \mathrm{sec}$ and 1.5 $\mathrm{mg} \cdot \mathrm{kg}^{-1}$ respectively).

All other comparisons were derived from bolus induction and are thus not directly comparable with the present investigation. Naguib, ${ }^{8,9}$ Short, ${ }^{4,5}$ van Hemelrijck ${ }^{10}$ and Vinik ${ }^{6}$ report $\mathrm{ED}_{50}$ values for anes- thesia induction of $1-1.5 \mathrm{mg} \cdot \mathrm{kg}^{-1}$ for propofol alone, slightly lower than ours (hypnotic [LVC]: $1.7 \mathrm{mg} \cdot \mathrm{kg}^{-1}$; motor [DF]: $1.6 \mathrm{mg} \cdot \mathrm{kg}^{-1}$; Table III). For a slightly differently configured analgesic endpoint, Short ${ }^{5}$ determined a propofol $\mathrm{ED}_{50}$ of $1.97 \mathrm{mg} \cdot \mathrm{kg}^{-1}$, lower than our LRP value of $3.3 \mathrm{mg} \cdot \mathrm{kg}^{-1}$. The higher doses in our study, as compared to bolus administration, are likely to be the result of infusion titration methodology. Slow infusion tends to result in longer times and higher doses due to ongoing redistribution into the "fast compartment" as well as overshoot. ${ }^{2}$ Useful quantitative comparison between these studies and ours is limited by the differences in experimental design.

Using a bolus technique and varying doses of both midazolam and propofol in fixed proportions (our study: fixed midazolam dose, therefore varying proportions), both Short ${ }^{4,5}$ and Vinik 6 showed significant supra-additive interactions between the two drugs for hypnotic (and Short, ${ }^{5}$ for antinociceptive) $\mathrm{ED}_{50}$ endpoints. In females undergoing dilatation and curettage, ${ }^{11}$ iv premedication with midazolam $0.03 \mu \mathrm{gg} \cdot \mathrm{kg}^{-1}$ 
reduced time to loss of lid reflex by about $40 \%$ from 75 to $44 \mathrm{sec}$ (our study: about $20 \% ; 232$ vs $180 \mathrm{sec}$ ) without affecting dose. Again the differences in methodology between our study and the studies cited preclude meaningful quantitative comparisons. In particular the design of the present study does not permit the construction of isobolograms and hence conclusions as to supra-or infra-additivity.

We have previously conducted a study of identical design using a thiopental infusion at $55 \mathrm{mg} \cdot \mathrm{kg}^{-1} \cdot \mathrm{hr}^{-1}$, approximately equipotent to the present dosage of propofol. While such a comparison of two studies must be treated with due caution, it is interesting to note that the reported scale of the dose reduction due to midazolam premedication is similar for both drugs (for $\mathrm{ED}_{50}$ : thiopental $12-19 \%$, propofol $13-20 \%$; for $\mathrm{ED}_{9 \dot{3}}$ thiopental 10-34\%, propofol 11-41\%). Other similarities include the large thiopental dose reduction (31\%) with midazolam premedication from $\mathrm{ED}_{50}$ to $\mathrm{ED}_{95}$ for antinociception, and the median dose endpoint ratio for the antinociceptive $v s$ hypnotic endpoint (LRP:LVC) of about two. Suggested differences are the higher "safety margin" between EEG burst suppression and surgical analgesia for thiopental, and the large motor endpoint (DF) thiopental dose reduction (29\%) from $\mathrm{ED}_{50}$ to $\mathrm{ED}_{95}$ with midazolam premedication.

The infusion titration model we chose for this study is well-validated and has several advantages compared to bolus methodologies. ${ }^{2,3} \mathrm{~A}$ major benefit is the ability to study multiple endpoints in one patient and session; other advantages include that timing and dosage values derived are applicable to every-day clinical bolus administration., ${ }^{2,3}$ Results of this model may become rate-dependent at higher infusion rates. This has not been formally studied for propofol, but for thiopental, ${ }^{12}$ infusion rate dependence has been demonstrated for infusion rates of 150-1200 $\mathrm{mg} \cdot \mathrm{min}^{-1}$, approximately equivalent to propofol $80-650 \mathrm{mg} \cdot \mathrm{min}^{-1}$ and well above the infusion rates used in our study.

We chose to give midazolam to our patients $20 \mathrm{~min}$ before anesthesia induction because we wanted to simulate typical premedication at our department - as opposed to co-induction - and to enable us to obtain a stable baseline EEG under midazolam premedication. The dose of midazolam chosen is standard for $i v$ premedication at our institution and is within the range typically quoted in the literature ${ }^{3-6,11}$ Threecompartment pharmacokinetic computer simulation (IVA-SIM, J. Schüttler and S. Kloos, Institut für Anaesthesiologie, Bonn University, Germany, (c) 1989-1991) predicts that our regime will achieve peak effect site midazolam levels of approximately 0.11 $\mu \mathrm{g} \cdot \mathrm{ml}^{-1}$ seven minutes after injection, falling by a third to approximately $0.07 \mu \mathrm{g} \cdot \mathrm{ml}^{-1}$ at the time of anesthesia induction 20 min after midazolam injection, and falling by another third to about $0.03 \mu \mathrm{g} \cdot \mathrm{ml}^{-1}$ around the time EEG burst suppression was typically achieved some 70 min after premedication.

Numerous studies have used and validated the endpoints loss of verbal contact and dropping an object as relevant measures for the induction of anesthesia. ${ }^{4-6,9}$ Loss of reaction to tetanic transcutaneous electrical stimulation has been described and utilized as a surrogate marker for surgical analgesia in several investigations ${ }^{4,5}$ while the attainment of EEG burst suppression is particularly relevant in the intensive care context.

Our study suggests that the two commonly used induction endpoints of loss of verbal contact (hypnotic endpoint; LVC) and dropping an object (motor endpoint; $\mathrm{DF}$ ) are equivalent with regard to timing and dosage. It is important to realize that the endpoint representing surgical analgesia (i.e., antinociception, LRP) is distinct from the hypnotic endpoint

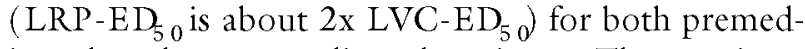
icated and unpremedicated patients. Thus patients unresponsive to pain can be presumed to be asleep but not vice-persa. Patients sedated to EEG burst suppression by propofol can safely be assumed to be adequately protected against nociception $\left(\mathrm{ED}_{50}-\mathrm{BUR}\right.$ is about $1 \frac{1}{2} \times \mathrm{LRP}-\mathrm{ED}_{5} \alpha$, again with and without midazolam premedication.

Both propofol and benzodiazepines act at the gamma-amino-butyric acid A $\left(\mathrm{GABA}_{\mathrm{A}}\right)$ receptor. $^{13}$ Recent experimental work ${ }^{13}$ demonstrates that propofol-midazolam interactions are dependent on the concentration of GABA at the receptor, suggesting that the nature and extent of propofol-benzodiazepine interactions should change with changing ratios of the two drugs, in accordance with our results showing differences in the interaction from $\mathrm{ED}_{50}$ to $\mathrm{ED}_{95}$. This is particularly visible for the nociceptive endpoint, likely to involve more subcortical or spinal elements than the hypnotic or EEG burst suppression endpoints. For unpremedicated patients the propofol dose-response curve for nociception (LRP) is flatter than for other endpoints, and midazolam premedication is accompanied by significant (non-parallel) steepening of the dose-response curve. Such non-parallel shifting of the dose-response curve points to a change in underlying pharmacological mechanisms. These changes might be due to the above-mentioned changes in interactions within the $\mathrm{GABA}_{\mathrm{A}}$ receptor complex, ${ }^{13}$ but may also include increased access to other central nervous system biophases (e.g., spinal or subcortical $v s$ cortical) or the recruitment of other receptor populations with increas- 
ing propofol concentrations. Overall, the differences of interaction at the different anesthetic endpoints under study are likely to be the consequence of the unique pharmacokinetic (biophase access) as well as pharmacodynamic (internal and external pattern of receptor activation) characteristics of each of their biophases.

In summary, propofol dose requirements are reduced at multiple anesthetic endpoints by midazolam premedication, without concomitant hemodynamic changes. The interaction is most marked for antinociception. The characteristics of the interaction depend upon the anesthetic endpoint chosen as well as the dose of propofol. The dosages of propofol needed to attain hypnosis, analgesia and EEG burst suppression are distinct in both unpremedicated and premedicated patients. Patients receiving propofol monoanesthesia who exhibit EEG burst suppression can therefore safely be presumed to have surgical analgesia, whereas patients who have just achieved hypnosis with propofol should not be assumed to be adequately protected against surgical nociception. We suggest that future studies of drug interaction in anesthesia include multiple relevant endpoints and that further efforts be made to understand the nature of the different biophases involved.

\section{Acknowledgments}

The authors would like to thank Dr. D. Bettex for aiding with data collection, Mrs C. Rodriguez for assistance with EEG recording, and Roche Pharma $(\mathrm{CH})$ $A G$ for partial financial support.

\section{References}

1 Apram MJ, Sanghpi R, Henthorn TK, et al. Determinants of thiopental induction dose requirements. Anesth Analg 1993; 76: 10-7.

2 Jacobs $J R$, Repes JG. Effect site equilibration time is a determinant of induction dose requirement (Editorial). Anesth Analg 1993; 76:1-6.

3 Wilder-Smith OHG, Ravussin PA, Decosterd LA, Despland PA, Bissonnette B. Midazolam premedication and thiopental induction of anaesthesia: interactions at multiple endpoints. Br J Anaesth 1999; 83: 590-5.

4 Short TG, Chui PT. Propofol and midazolam act synergistically in combination. Br J Anaesth 1991; 67: $539-45$.

5 Short TG, Plummer JL, Chui PT. Hypnotic and anaesthetic interactions between midazolam, propofol and alfentanil. Br J Anaesth 1992; 69: 162-7.

6 Vinik HR, Bradley EL, Kissin I. Triple anesthetic combination: propofol-midazolam-alfentanil. Anesth Analg 1994; 78: 354-8.

7 Peacock JE, Spiers SP, McLauchlan GA, Edmondson WC, Berthoud M, Reilly CS. Infusion of propofol to identify smallest effective doses for induction of anaesthesia in young and elderly patients. Br J Anaesth 1992; 69: 363-7.

8 Naguib M, Sari-Kouzel A Thiopentone-propofol hypnotic synergism in patients. Br J Anaesth 1991; 67: 4-6.

9 Naguib M, Sari-Kouzel A, Seraj M, el-Gammal M, Gomma M. Induction dose-responses studies with propofol and thiopentone. Br J Anaesth 1992; 68: 308-10.

10 Van Hemelrijck J, Muller P, Van Aken H, White PF. Relative potency of eltanolone, propofol, and thiopental for induction of anesthesia. Anesthesiology 1994; 80: 36-41.

11 Oxom DC, Ferris LE, Harrington E, Orser BA. The effects of midazolam on propofol-induced anesthesia: propofol dose requirements, mood profiles, and perioperative dreams. Anesth Analg 1997; 85: 553-9.

12 Gentry WB, Krejcie TC, Henthorn TK, et al. Effect of infusion rate on thiopental dose-response relationships. Assessment of a pharmacokinetic-pharmacodynamic model. Anesthesiology 1994; 81: 316-24.

13 McAdam LC, MacDonald JF, Orser BA. Isobolographic analysis of the interactions between midazolam and propofol at $\mathrm{GABA}$ receptors in embryonic mouse neurons. Anesthesiology 1998; 89: 1444-54. 